Dokuz Eylül Üniversitesi-Mühendislik Fakültesi

Fen ve Mühendislik Dergisi

Cilt 20, Sayı 60, Eylül, 2018
Dokuz Eylul University-Faculty of Engineering Journal of Science and Engineering Volume 20, Issue 60, September, 2018

DOI: $10.21205 /$ deufmd. 2018206074

\title{
Öncelik Seviyelerine Sahip Çoklu Yetenek Gerektiren İşler için Ekip Oluşturma, Çizelgeleme ve Rotalama
}

\author{
Gözde KUTAYER BILLGIN*1, Eda YÜCEL ${ }^{2}$, Gültekin KUYZU \\ TOBB Ekonomi ve Teknoloji Üniversitesi, Mühendislik Fakültesi, Endüstri Mühendisliği Bölümü, \\ 06510, Ankara \\ ${ }^{1}$ (ORCID: 0000-0002-2532-7136) \\ 2(ORCID: 0000-0002-3448-1522) \\ 3(ORCID: 0000-0002-1997-306X)
}

(Alınıs / Received: 08.01.2018, Kabul / Accepted: 16.05.2018, Online Yayınlanma / Published Online: 15.09.2018

\begin{abstract}
Anahtar Kelimeler Özet: $\mathrm{Bu}$ çalışmada, tüm saha hizmet operasyonlarında İşgücü çizelgeleme ve rotalama, Modelleme, Sezgisel yöntemler, Takım oluşturma, Çok amaçlı karar verme gözlemlenen, çoklu yetenek gereksinimi içeren işgücü rotalama ve çizelgeleme problemi ele alınmıștır. Problem, gerçek hayatta enerji dağıtım şirketlerinin günlük olarak karşılaştığı bir planlama probleminden yola çıkılarak tanımlanmıştır. Amaç, farklı konumları, öncelikleri ve yetenek gereksinimleri olan işler için; uygun teknisyen ekiplerinin ve sıralı iș listelerinin optimal bir şekilde belirlenmesidir. Öncelikle, problem için iki öncelikli amaç fonksiyonu bulunan bir matematiksel model geliştirilmiştir. Problem boyutu büyüdükçe modelin kabul edilebilir sürede ve kalitede çözüm vermemesi nedeniyle, büyük ölçekli problemler için kısa sürede kaliteli çözümler üreten, üç așamalı bir sezgisel yöntem geliștirilmiștir. Geliștirilen yöntemin etkinliği hem rastgele türetilmiş, hem de gerçekçi veri kümeleri üzerinde gösterilmiștir.
\end{abstract}

\section{Forming, Scheduling and Routing Field Service Teams for Multi-Skill Prioritized Tasks}

\begin{tabular}{l}
\hline Keywords \\
Workforce \\
scheduling and \\
routing, \\
Modelling, \\
Heuristics, Team \\
forming, Multi \\
objective decision \\
making
\end{tabular}

\begin{abstract}
In this research, we study the multi-skill workforce scheduling and routing problem that arises in all field service operations. The problem originates from a daily planning problem faced by the electricity distribution companies. Given a set of geographically dispersed tasks with different priorities and skill requirements, and a set of technicians with different skills; the objective is to form teams of technicians while assigning a sequence of tasks to each team in an optimal manner. First, we develop a mathematical model that has two prioritized objective functions for the problem. Since the solution time and quality of the model degrades quickly as the problem size increases, we devise a threephased heuristic that generates good solutions efficiently for large-
\end{abstract}


G. Kutayer Bilgin vd. / Öncelik Seviyelerine Sahip Çoklu Yetenek Gerektiren İşler için Ekip Oluşturma, Çizelgeleme ve Rotalama

scale problems. We demonstrate the performance of the heuristic through randomly generated and realistic problem instances.

*Sorumlu yazar: gkutayer@gmail.com

\section{Giriş}

Yerinde servis hizmetlerine, diğer bir deyişle, servis hizmetlerinin müşterilerin bulunduğu yerde verilmesine duyulan ihtiyaç gün geçtikçe artmaktadır. Teknisyenlerin müşteri noktalarında sundukları servis hizmetleri, evde sunulan sağlık hizmetleri, güvenlik şirketlerinin sundukları kontrol hizmetleri; yerinde servis hizmeti kullanım alanları arasındadır. Gerçek hayatta bu alanlarda karşılaşılan, teknisyenlerin müșterilere ait mülkiyetlerde gerçekleștirecekleri bakım veya tamir faaliyetlerinin çizelgelenmesi, gezici sağlık ekiplerinin ya da hemşirelerin görev çizelgelerinin hazırlanması, güvenlik ekiplerinin belirlenen tüm hedef alanı rotalayacak şekilde günlük-saatlik rotalarının belirlenmesi gibi problemler, işgücü çizelgeleme ve rotalama problemleri (IÇRP) olarak ele alınmaktadır.

Servis sektöründeki tüm alanlarda olduğu gibi, yerinde servis sektöründe de hizmet kalitesini artırarak maliyetleri düşürme ihtiyacı bulunmaktadır [1]. Bu nedenle, yerinde servis hizmetlerinin tüm uygulama alanlarında temel amaç, rotalama ve çizelgeleme içeren operasyonel planlamayı yüksek hizmet kalitesi ve düşük maliyet ile gerçekleştirmektir.

Literatürde, yerinde servis hizmetlerine ilişkin problemlerin ele alındığı çalışmalara bakıldığında örnek olarak, evde sunulan sağllk hizmetleri [2], ev hizmetleri [3], teknisyenlerin müşteri noktalarında sundukları servis, bakım veya tamirat hizmetleri [4] ve güvenlik

şirketlerinin farklı müşteri konumları için sundukları kontrol hizmetleri [5] verilebilir.
Çalışmamızda, genelde yerinde servis hizmeti sağlayan tüm servis operasyonlarında, özelde enerji dağıtım sektöründe gözlemlenen yetenek gereksinimleri varlığında işgücü çizelgeleme ve rotalama problemi ele alınmıştır. Problem, Enerji Dağıtım sektöründe faaliyet gösteren şirketlerin karşılaştı̆̆ ve günlük olarak çözülmesi gereken operasyonel problemlerden biri olan, sahadaki ekiplerin ve işlerin daha etkin bir șekilde takibi ve atanması problemidir. Problemde, ișlerin zaman sınırları, farklı ve çoklu yetenek gereksinimleri, takım oluşturma ihtiyacı ve iş servis süreleri dikkate alınmaktadır.

Makalenin devamında, Bölüm 2'de ilgili literatür taramasına, Bölüm 3'te problem tanımına yer verilmiştir. Problem için geliştirilen matematiksel model Bölüm 4'te, sezgisel yöntem ise Bölüm 5'te anlatılmıştır. Bölüm $6^{\prime}$ da önerilen yöntemlerin hesaplamalı analizlerine ilişkin sonuçlar verilmiştir. Son olarak, Bölüm 7'de ise yapılan çalışmaya ilişkin bulgular özetlenmiştir.

\section{Literatür}

Literatürdeki İÇRP çalışmalarının; amaç, planlama çevreni, işgücünün homojen veya heterojen olma durumu (tek ya da çoklu yetenek varlığı), işlerin zaman sinırının olma durumu, tek modlu ya da çok modlu ulaşım seçeneğinin bulunması, ekip olușturma gerekliliği, ișler arasında bağımlılık olması, işlerin farklı önceliklere sahip olması gibi özelliklere göre farklılaştığı gözlemlenmiştir. Her bir özellik için literatürdeki farklı yaklaşımlar ve çalışmamızda ne şekilde ele alındığı aşağıda açıklanmaktadır.

Literatürde yer alan İÇRP çalışmalarında; çalışan sayısının en küçüklenmesi [6], operasyonel (ulaşım, fazla mesai vb.) 
G. Kutayer Bilgin vd. / Öncelik Seviyelerine Sahip Çoklu Yetenek Gerektiren İșler için Ekip Olușturma, Çizelgeleme ve Rotalama

maliyetlerin en küçüklenmesi ([7], [8], dikkate alındığı, işlerin son teslim [9]), işlerin en kısa sürede tamamlanması ([4], [10]), atanan iş sayısının en büyüklenmesi [11] veya bunların birden fazlasının ve çeşitli kısıtların ihlalinin ağırlıklandırılmış toplamının eniyilenmesi ([12], [13]) gibi birçok farklı amaç fonksiyonuna rastlanmaktadır. Çalışmamızda ele alınan problemde ise, işler eşit öncelik seviyesine sahip değildir ve operasyonel maliyetlerin düşürülmesi amacının yanı sıra yüksek öneme sahip işlerin, düşük öneme sahip işlerden önce gerçekleștirilmesi amacı da bulunmaktadır. $\mathrm{Bu}$ nedenle, problem kapsamında çoklu önceliklendirilmiş amaç fonksiyonları kullanılmıștır. Birinci öncelikli amaç, Cordeau vd. [4] ve Fırat ve Hurkens [10]'in çalışmalarında ele aldıkları gibi önceliklerine göre ağırlıklandırılmış işlerin öncelikli tamamlanma süreleri toplamını en küçüklemektir. İkinci öncelikli amaç ise, seyahat maliyetlerini, fazla mesai maliyetlerini ve geciken işlerden kaynaklanan ceza maliyetlerini içeren toplam operasyonel maliyetlerin en küçüklenmesidir.

Servis sektöründeki işgücü çizelgeleme ve rotalama problemlerinde, etkin rotalama yapılmadığında, çalışanlar gün içinde çalıştıkları süreden daha fazla zamanı seyahat ederek kaybedebilmektedir. Bunun sonucunda işlerin teslim sürelerinin aşıması söz konusu olmaktadır. Çalışanların seyahat sürelerini düşürmek büyük önem taşımaktadır [14]. Yerinde servis sektöründeki işgücü çizelgeleme çalışmalarının bir bölümü ise problemin rotalama boyutunu ihmal etmektedir. Örneğin, çalışmamızda ele alınan probleme pek çok açıdan benzerlik gösteren Cordeau vd. [4] ve Firat ve Hurkens [10] işgücü çizelgeleme problemini çalışmış, ancak çalışmaları kapsamında rotalamayı ele almamışlardır. Çalışmamızda ise, çalışanların seyahat sürelerinin de tarihlerini geçirmeyecek şekilde bir rotalama yapılması hedeflenmektedir.

İşgücü çizelgeleme ve rotalama problemlerinde, çalışanlar arasında yetenek farklılıklarının olduğu durumlar bulunmaktadır. Literatürde yer alan bazı İÇRP çalışmaları ([15], [16], [17]), bu farklılıkları ihmal etmektedir. Cordeau vd. [4], Firat ve Hurkens [10], Kovacs vd. [4] ve Zamorano ve Stolletz [9] ise, çalışanların farklı yeteneklere sahip olduğu durumları ele almıştır. Çalışmamızda da, işlerin farklı yetenek gereksinimleri bulunması ve teknisyenlerin farklı yeteneklere sahip olması durumu dikkate alınmıştır.

Literatürde yer alan İÇR çalışmalarında planlama ufku, tek-periyotlu (sürekli zaman) ve çok-periyotlu olmak üzere iki şekilde ele alınmaktadır. Optimizasyon problemlerinde, genelde, çok-periyotlu yaklaşım stratejik karar verme seviyesinde, tek-periyotlu yaklașımı ise operasyonel karar verme seviyesinde kullanılmaktadır. Literatürdeki çokperiyotlu İÇRP çalışmalarının ([9], [19], [20], [15], [16], [21], [22]) ise, stratejik karar verme değil, operasyonel karar verme seviyesinde oldukları görülmektedir. Operasyonel problem çalışılmasına rağmen çok-periyotlu olarak ele alınma nedeni, periyodik ziyaret gereksiniminin bulunmasıdır. Çok-periyotlu planlama, planlama ufkunun büyük oluşundan kaynaklı olarak, daha kapsamlı çalışma saati düzenlemelerinin dikkate alınmasını gerektirmektedir. Çok periyotlu İÇRP çalışmalarından Blakeley vd. [19] çoklu yetenek seviyeleri varlığında, çokperiyotlu teknisyen çizelgeleme ve rotalama problemini çalışmış ancak çalışmamızda ele alınan problemden farklı olarak, takım oluşturma kararlarını dâhil etmemiştir. Tang vd. [20] teknisyenlerin farklı konumlardaki bakım işlerine atanması ve rotalarının 
belirlenmesi problemini çok-periyotlu gerekliliğini beraberinde getirmektedir. olarak çalışmış ancak teknisyenlerin Çalışmamıza benzer şekilde, Cordeau vd. hepsinin aynı yeteneğe sahip olduğunu [4], Firat ve Hurkens [10], Kovacs vd. [7] varsaymıştır. Hindle vd. [23], Cordeau vd. ve Zamorano ve Stolletz [9] çalışanların [4], Kovacs vd. [7], Rest ve Hirsch [24] çalışmalarında tek bir günü içeren sürekli planlama ufkuna yer vermiştir. Çalışmamızda da, çoklu yetenek gereksinimlerine sahip işlerin çoklu yeteneklere sahip teknisyenlerden oluşan ekiplere, tek-periyotlu (sürekli planlama ufku) olacak şekilde günlük iş planlarının atanması ve ekiplerin günlük rotalarının belirlenmesi problemi çalışılmıştır.

Çalışmamızda ele alınan problem, gerçek hayatta enerji dağıtım sektöründe karşılaşılan bir problem olduğu için, işlerin belirli bir zaman sınırında gerçekleştirilmesi gerekmektedir. Benzer şekilde, Cordeau vd. [4]'nin çalıștığı teknisyen - görev atama probleminde de, işlerin belirli bir zaman sınırında tamamlanması gerekliliği ve işin zaman sinırına uyulmaması durumunda ceza maliyetinin ortaya çıkması ele alınmıştır. Tang vd. [20] teknisyenlerin işlere atanması ve rotalanması problemini ele almıştır fakat çalışmalarında işlerin belirli bir zaman sınırında bitirilme gerekliliğini bulunmamaktadır.

Literatürde yer alan İÇRP problemlerinde, farklı ulaşım çeşitleri (özel bir araç, toplu taşıma, bisiklet ya da yürüyüş) kullanıldığı görülmektedir. Örneğin; Hiermann vd. [11] ve Fikar vd. [1] sağlık çalışanlarının toplu taşıma ile seyahat etme durumlarını ele almıştır. Çalışmamızda ise, ekipler, atanan işleri gerçekleştirmek için gerekli ekipmanları firmaya ait servis araçlarında taşımakta ve bu araçlarla seyahat etmektedir. Bu nedenle, problemimizde tek bir ulaşım modu olduğu varsayılmaktadır.

Literatürde, bir işi birden fazla çalışanın aynı anda yapma gerekliliği bazı çalışmalarda eş zamanlılık olarak ele alınmaktadır. Bu durum, ekip oluşturma

yeteneklerine göre ekiplerin oluşturulması ve bu ekiplere işlerin atanması birlikte ele alınmaktadır.

Literatürde yer alan bazı İÇRP çalışmalarında, işler arasında zamana bağlı ilişkiler (öncüllük - ardıllık ilişkisi) bulunmaktadır. Cordeau vd. [4] ve Goel ve Meisel [17] atanacak işler arasında bağlı bir ilişki bulunmasını ele almaktadır. Kovacs vd. [7]'nin ve Zamorano ve Stolletz [9]'in çalışmalarında ise, problemimize benzer şekilde, işler arasında bağlı ilişkiler bulunmamaktadır.

Literatürde yer alan çalışmalardan Lanzarone ve Matta [25], talepte başka bir deyişle iş kümesinde rassallığı; Yuan vd. [26] ise servis sürelerindeki rassallığı ele almıştır. Çalışmamızda ise, iş kümesinin ve servis sürelerinin deterministik olduğu varsayılmaktadır.

Özetle; çalışmamızda, literatürdeki diğer IÇRP çalışmalarından farklı olarak, farklı coğrafi konumlardaki çoklu yetenek gereksinimlerine sahip ve zaman sınırı bulunan ișlerin sürekli planlama çevreninde gerçekleştirilmesi için, farklı yetenekler içeren teknisyenlerden ekip oluşturulması, işlerin ekiplere atanması ve ekiplerin rotalarının belirlenmesi problemi ele alınmıștır. Problemde öncelikli iki amaç bulunmaktadır. Birinci öncelikli amaç, önceliklerine göre ağırlıklandırılmış iş sınıflarının tamamlanma sürelerinin ağırlıklı toplamını en küçüklemektir. İkinci öncelikli amaç ise; seyahat maliyetlerini, fazla mesai maliyetlerini ve geciken işlerden kaynaklanan ceza maliyetlerini içeren günlük operasyonel maliyetleri en küçüklemektir. Çalışmamız kapsamında, problemin küçük ölçekli örneklerinin çözümü için bir matematiksel model, 
G. Kutayer Bilgin vd. / Öncelik Seviyelerine Sahip Çoklu Yetenek Gerektiren İşler için Ekip Oluşturma, Çizelgeleme ve Rotalama

büyük ölçekli problem örnekleri için ise uyulması gereken kurallara göre bir sezgisel yöntem geliştirilmiştir.

\section{Problem tanımı}

Hizmet verilen bölge bir çizge olarak ele alınırsa, $\boldsymbol{G}=\left(\boldsymbol{N}^{\prime}, \boldsymbol{A}\right)$ tüm bölgeyi ifade etmektedir. $\boldsymbol{N}=\{\mathbf{1}, \ldots, \boldsymbol{n}\}$ kümesi farklı coğrafi konumlardaki işleri belirtmektedir. $\mathbf{0}$ ve $\boldsymbol{n}+\mathbf{1}$ düğümleri, merkez konumu temsil eden etkisiz düğ̈̈mleri, $\quad \boldsymbol{N}^{\prime}=\boldsymbol{N} \cup\{\mathbf{0}, \boldsymbol{n}+\mathbf{1}\} \quad$ ise düğ̈̈m kümesini ifade etmektedir. $\boldsymbol{A}=$ $\left\{(i, j) \mid i \in N^{\prime} \backslash\{n+1\}, j \in N^{\prime} \backslash\{0\}, i \neq j\right\}$ kümesindeki ayrıtlar ise, işlerin konumları arasındaki yolları tanımlamaktadır. Her $(\boldsymbol{i}, \boldsymbol{j}) \in \boldsymbol{A}$ ayrıtı için $\boldsymbol{i}$ işinden $\boldsymbol{j}$ işine ulaşma süresi $\boldsymbol{t}_{\boldsymbol{i} \boldsymbol{j}}$, seyahat maliyeti ise $\boldsymbol{c}_{\boldsymbol{i}}^{\boldsymbol{I}}$ olarak ifade edilmektedir. Her bir iş $\boldsymbol{i} \in \boldsymbol{N}$ için $\boldsymbol{P}_{\boldsymbol{i}}$ işin işlem süresini belirtir ve sabittir, işe atanan teknisyen sayısına bağlı olarak değişmez. Her ekip, en fazla $\boldsymbol{v}$ adet teknisyenden olușmaktadır. Bir teknisyen en fazla bir ekibe atanabilmektedir. $\boldsymbol{Q}$, yetenek kümesini; $\boldsymbol{q} \boldsymbol{\epsilon} \boldsymbol{Q}$ ise, $\boldsymbol{Q}$ yetenek kümesinde yer alan bir yeteneği ifade etmektedir. Her iş $\boldsymbol{i} \boldsymbol{\epsilon} \boldsymbol{N}$ için, yetenek gereksinimleri $\boldsymbol{u}_{\boldsymbol{i q}}$; teknisyenlerin yetenek seviyeleri ise $\boldsymbol{g}_{\boldsymbol{m} \boldsymbol{q}}$ 0-1 ikili parametreleri ile tanımlanmaktadır. Planlama çevreni bir gündür ve $\left(\boldsymbol{0}, \boldsymbol{\tau}_{\text {max }}\right]$ zaman aralığı ile ifade edilmektedir. Planlama çevreninde her teknisyen için normal mesai $(\mathbf{0}, \boldsymbol{\tau}]$ zaman aralığına karşılık gelmekte, $(\boldsymbol{\tau}$, $\left.\tau_{\text {max }}\right]$ aralığındaki çalışmalar ise fazla mesai olarak nitelendirilmektedir. Her birim fazla mesai için $\boldsymbol{c}^{\boldsymbol{I I}}$ fazla mesai maliyeti ödenmektedir. $\boldsymbol{\tau}_{\boldsymbol{m a x}}$ 'in tüm işlerin ekiplerce gerçekleştirilebileceği kadar büyük bir değer olarak belirlendiği varsayılmaktadır. Her bir iş $\boldsymbol{i} \in \boldsymbol{N}$ için; $\boldsymbol{f}_{\boldsymbol{i}}$, işin tamamlanması gereken zaman sınırını belirtmektedir. İșin $\boldsymbol{f}_{i}{ }^{\prime}$ den sonra tamamlanması durumunda gecikilen her birim süre için $\boldsymbol{c}_{\boldsymbol{i}}^{\boldsymbol{I I I}}$ gecikme maliyeti ödenmektedir. $\boldsymbol{P}=\{\mathbf{1}, \ldots, \boldsymbol{\rho}\}$, işler için belirlenen öncelik sınıflarının kümesini ifade etmektedir. Her iş öncelik sınıfı $\boldsymbol{p} \in$ $\boldsymbol{P}$ 'nin ağırlı̆̆ $\boldsymbol{w}_{\boldsymbol{p}}$ ile ifade edilmektedir. Her bir iş $\boldsymbol{i} \in \boldsymbol{N}$ için; $\boldsymbol{a}_{\boldsymbol{i} \boldsymbol{p}} \quad 0-1 \quad$ ikili parametresi, $\boldsymbol{i}$ işinin $\boldsymbol{p} \in \boldsymbol{P}$ öncelik sınıfına ait olup olmadığını belirtmektedir. Bir iş mutlaka bir öncelik sınıfına aittir ve bir iş birden fazla öncelik sınıfında yer alamaz. Bir $\boldsymbol{p} \in \boldsymbol{P}$ öncelik sınıfındaki işlerden en geç tamamlanan işin tamamlanma süresi $\boldsymbol{C}_{\boldsymbol{p}}^{\max }$ ile gösterilmektedir.

\section{Matematiksel Model}

Çalışmamızda ele alınan problemin çözümü için öncelikle karma tam sayılı programlama modeli geliștirilmiștir.

\section{Kümeler:}

$\boldsymbol{N}$ : Farklı coğrafi konumlarda bulunan işlerin kümesi, $\{\mathbf{1}, \ldots, \boldsymbol{n}\}$

$\boldsymbol{N}^{\prime}$ : Başlangıç ve bitiş yapay işlerini de içeren işler kümesi, $\{\mathbf{0}, \mathbf{1}, \ldots, \boldsymbol{n}+\mathbf{1}\}$

$\boldsymbol{M}$ : Teknisyen kümesi

$\boldsymbol{E}$ : Ekip kümesi (Maksimum ekip sayısı, yani $|\boldsymbol{E}|$; ekiplerin araçlı olması durumunda araç sayısına, herhangi bir kısıt olmadığı durumda teknisyen sayısına eşit olacak şekilde problem girdisi olarak belirlenmelidir.)

$Q$ : Yetenek kümesi

$P$ : Öncelik sınıfları kümesi

\section{Parametreler:}

$\boldsymbol{P}_{\boldsymbol{i}}: \boldsymbol{i}$ işinin işlem süresi, $\forall \boldsymbol{i} \in \boldsymbol{N}$

$\boldsymbol{u}_{i q}: \boldsymbol{i}$ işi $\boldsymbol{q}$ yeteneğine sahip bir teknisyen gerektiriyorsa 1 , diğer durumlarda 0 değerini alır. $\forall \boldsymbol{\forall} \in$ $N, q \in Q$

$\boldsymbol{g}_{\boldsymbol{m} \boldsymbol{q}}: \boldsymbol{m}$ teknisyeni $\boldsymbol{q}$ yeteneğine sahip ise 1 , diğer durumlarda 0 değerini alır. $\forall \boldsymbol{m} \in \boldsymbol{M}, \boldsymbol{q} \in \boldsymbol{Q}$

$\boldsymbol{a}_{i p}: \boldsymbol{i}$ işi $\boldsymbol{p}$ öncelik sınıfındaysa 1 , diğer durumlarda 0 değerini alır. $\forall \boldsymbol{i} \in$ $\boldsymbol{N}, \boldsymbol{p} \in \boldsymbol{P}$

$\boldsymbol{w}_{\boldsymbol{p}}: \boldsymbol{p}$ iş öncelik sınıfının ağırlığı, $\forall \boldsymbol{p} \in$ $P$

$\boldsymbol{t}_{\boldsymbol{i} \boldsymbol{j}}: \boldsymbol{i}$ düğümünden $\boldsymbol{j}$ düğümüne ulaşma süresi, $\forall(\boldsymbol{i}, \boldsymbol{j}) \in \boldsymbol{A}$ 
G. Kutayer Bilgin vd. / Öncelik Seviyelerine Sahip Çoklu Yetenek Gerektiren İşler için Ekip Oluşturma, Çizelgeleme ve Rotalama

$$
\begin{aligned}
& \boldsymbol{c}_{\boldsymbol{i j}}^{\boldsymbol{I}}: \boldsymbol{i} \text { işinden } \boldsymbol{j} \text { işine seyahat maliyeti, } \quad S_{n+1, k}-\tau \leq o_{k}, \forall k \in E \\
& \forall(\boldsymbol{i}, \boldsymbol{j}) \in \boldsymbol{N} \quad c_{p}^{\max } \geq a_{i p} * c_{i}, \forall i \in N, p \in P \\
& c^{\text {II }} \text { : Fazla mesai birim maliyeti } \\
& \boldsymbol{c}_{\boldsymbol{i}}^{\boldsymbol{I I I}}: \boldsymbol{i} \text { işinin birim gecikme } \\
& \text { maliyeti, } \forall \boldsymbol{\forall} \in \boldsymbol{N} \\
& \boldsymbol{f}_{\boldsymbol{i}}: \boldsymbol{i} \text { işinin tamamlanması gereken } \\
& \text { zaman sınırı, } \forall \boldsymbol{i} \in \boldsymbol{N} \\
& o_{k}, L_{i}, S_{i k}, c_{i}, c_{p}^{\max } \geq 0 \\
& \forall i \in N, p \in P, k \in E \\
& Y_{i k}, X_{i j k}, Z_{m k} \in\{0,1\} \text {, } \\
& \forall i \in N,(i, j) \in A, m \in M, k \in E
\end{aligned}
$$$$
\boldsymbol{\tau} \text { : Normal mesai zaman sınırı }
$$$$
\boldsymbol{\tau}_{\text {max }} \text { : Fazla mesai zaman sinırı }
$$$$
\boldsymbol{B} \text { : Büyük bir sayı }
$$

\section{Karar Değişkenleri:}

$\boldsymbol{S}_{\boldsymbol{i} \boldsymbol{k}}: \boldsymbol{i}$ işinin $\boldsymbol{k}$ ekibi tarafından tamamlanma zamanı, $\forall \boldsymbol{i} \in \boldsymbol{N}, \boldsymbol{k} \in \boldsymbol{E}$

$\boldsymbol{Z}_{\boldsymbol{m} \boldsymbol{k}}: \boldsymbol{m}$ teknisyeni $\boldsymbol{k}$ ekibine atanmışsa 1, diğer durumlarda 0 değerini alır, $\forall \boldsymbol{m} \in \boldsymbol{M}, \boldsymbol{k} \in \boldsymbol{E}$

$\boldsymbol{Y}_{\boldsymbol{i} \boldsymbol{k}}: \boldsymbol{i}$ işi $\boldsymbol{k}$ ekibine atanmışsa 1, diğer durumlarda 0 değerini alır, $\forall \boldsymbol{i} \in$ $\boldsymbol{N}, \boldsymbol{k} \in \boldsymbol{E}$

$\boldsymbol{X}_{\boldsymbol{i j k} \boldsymbol{k}}: \boldsymbol{k}$ ekibi $\boldsymbol{i}$ işini $\boldsymbol{j}$ işinden hemen önce ziyaret ederse 1 , diğer durumlarda 0 değerini alır, $\forall(\boldsymbol{i}, \boldsymbol{j}) \in \boldsymbol{A}, \boldsymbol{k} \in \boldsymbol{E}$

$\boldsymbol{c}_{\boldsymbol{i}}: \boldsymbol{i}$ işsinin tamamlanma zamanı, $\forall \boldsymbol{i} \in$ N

$\boldsymbol{L}_{\boldsymbol{i}}: \boldsymbol{i}$ işindeki gecikme miktarı, $\forall \boldsymbol{i} \in \boldsymbol{N}$

$\boldsymbol{o}_{\boldsymbol{k}}: \boldsymbol{k}$ ekibinin fazla mesai süresi, $\forall \boldsymbol{k} \in \boldsymbol{E}$

$\boldsymbol{C}_{\boldsymbol{p}}^{\text {max }}: \boldsymbol{p}$ öncelik sınıfındaki işlerden en geç tamamlanan işin tamamlanma süresi, $\forall \boldsymbol{p} \in \boldsymbol{P}$

$$
\begin{aligned}
& \text { Kisıtlar: } \\
& \sum_{j \in N} X_{0 j k}=1, \forall j \in N, k \in E \\
& \sum_{i \in N} X_{i, n+1, k}=1, \forall i \in N, k \in E \\
& \sum_{k \in E} Y_{i k}=1, \forall i \in N \\
& \sum_{j \in N} X_{i j k}=Y_{i k}, \forall i \in N, k \in E \\
& X_{i i k}=0, \forall i \in N^{\prime}, k \in E \\
& \sum_{i \in N^{\prime} \backslash\{n+1\}} X_{i j k}-\sum_{j \in N^{\prime} \backslash\{0\}} X_{j i k}=0 \\
& \quad \forall j \in N, k \in E \\
& S_{i k} \leq c_{i}, \forall i \in N, k \in E \\
& \left(S_{i k}+t_{i j}+P_{j}-S_{j k}\right) \leq B *\left(1-X_{i j k}\right) \\
& \quad \forall(i, j) \in A, k \in E \\
& \sum_{k \in K} Z_{m k} \leq 1, \forall m \in M \\
& \sum_{m \in M} Z_{m k} \leq v, \forall k \in E \\
& u_{i q} * y_{i k} \leq \sum_{m \in M}\left(g_{m q} * Z_{m k}\right) \\
& \quad \forall i \in N, k \in E, q \in Q \\
& c_{i}-f_{i} \leq L_{i}, \forall i \in N \\
& S_{n+1, k} \leq \tau_{m a x}, \forall k \in E
\end{aligned}
$$

Kısıt (1), her ekibin günlük rotasının merkezde başlamasını sağlar. Kısıt (2), her ekibin günlük rotasının merkezde bitmesini sağlar. Kısıt (3), her ișin sadece bir ekip tarafından yapılmasını sağlar. Kısıt (4), bir iş bir ekibe atanmışsa, ekibin rotasında bu ișin bulunmasını sağlar. Kısıt (5), ekip rotalarında tek iş içeren alt turların oluşmasını engeller. Kısıt (6), bir ekibe bir iş atanmışsa, ekibin bu işe ait düğüme başka bir düğümden gelip, bu işten sonra başka bir dügüme gitmesini, yani planlanan ziyaretlerde akışın korunmasını sağlar. Kısıt (7), bir işin tamamlanma zamanının o işin atandığı ekibin işi tamamlama süresi olarak hesaplanmasını sağlar. Kısıt (8), bir işe atanan ardışık işlerden, önceki bitmeden sonrakine başlanamamasını sağlar. Böylece alt turlarin bertaraf edilmesi sağlanmış olur. Kısıt (9), bir teknisyenin en fazla bir ekibe atanabilmesini sağlar. Kisıt (10), bir ekibe atanabilecek teknisyen sayısını sınırlar. Bir ekibe hiç bir teknisyen atanmaması mümkündür. Kısıt (11), bir işin atandığı ekipte çalışan teknisyenlerin sahip oldukları yetenekler ile o iş için sahip olunması gereken yeteneklerin uyumlu olmasını sağlar. Kısıt (12), var ise, işteki gecikme miktarını hesaplar. Kisıt (13), bir ekibe maksimum mesai süresini aşan bir iş planı atanmamasını garantiler. Kısıt (14), bir ekip, fazla mesai yapıyor ise, fazla mesai süresini hesaplar. Kısıt (15), bir iş öncelik sınıfı için, o sınıftaki işlerden en geç biteninin tamamlanma zamanını hesaplar. Kısıt (16), karar değişkenleri için negatif değerde olmama durumunu tanımlar. Kısıt (17), karar değişkenleri için 0-1 ikili değişken olma durumunu tanimlar. 
G. Kutayer Bilgin vd. / Öncelik Seviyelerine Sahip Çoklu Yetenek Gerektiren İşler için Ekip Oluşturma, Çizelgeleme ve Rotalama

Model kapsamında iki öncelikli amaç fonksiyonu bulunmaktadır. Birinci öncelikli amaç için, önceliklerine göre ağırlıklandırılmıș iș sınıflarının ağırlıklandırılmış tamamlanma süresi toplamını en küçüklemeyi hedefleyen $M 1$ modeli çözülür. $M 1$ modeli aşağıdaki gibidir:

En küçükle

$$
\sum_{p \in P} w_{p} C_{p}^{\max }
$$

Öyle ki:

İkinci öncelikli amaç için ise, $M 1$ modelinden elde edilen en iyi çözümde her öncelik sınıfı için elde edilen $\boldsymbol{C}_{\boldsymbol{p}}^{\max (*)}$ optimal değerleri kullanılarak operasyonel maliyetleri en küçüklemeyi hedefleyen $M 2$ modeli çözülür. $M 2$ modeli aşağıdaki gibidir:

$$
\begin{aligned}
\sum_{k \in E}^{\text {En küçükle }} \sum_{i, j \in N} X_{i j k} & c_{i j}^{I}+\sum_{k \in E} o_{k} c^{I I} \\
& +\sum_{i \in N} L_{i} c_{i}^{I I I}
\end{aligned}
$$

Öyle ki:

$$
C_{p}^{\max } \leq C_{p}^{(1)-(17)} \gamma_{p}^{\max (*)}, \forall p \in \mathrm{P}
$$

Yeni eklenen Kısıt (20) ile $M 2$ modeli, her bir $\boldsymbol{p} \in \boldsymbol{P}$ iş sınıfının tamamlanma süresinin $M 1$ modelinin en iyi çözümündeki tamamlanma süresinin en fazla $\boldsymbol{\gamma}_{\boldsymbol{p}}\left(\boldsymbol{\gamma}_{\boldsymbol{p}} \geq 1\right)$ katı kadar olmasına izin verir. Bir öncelik sınıfı için $\gamma_{p}=1$ seçilmesi durumunda, o öncelik sınıfı için M1 modelinin çözümü ile bulunan optimal $\boldsymbol{C}_{\boldsymbol{p}}^{\max (*)}$ değerinin korunması hedeflenir.

Geliştirilen matematiksel model farklı boyutlardaki problem örnekleri üzerinde analiz edilmiştir. $\mathrm{Bu}$ analizlere ilişkin sonuçlar Bölüm 6'da paylaşılmaktadır. Yapılan analizlerde, problem örneklerinin boyutu büyüdükçe modelin kabul edilebilir sürede, kabul edilebilir kalitede çözüm üretmediği gözlenmiştir.

\section{Sezgisel Çözüm Yöntemi}

Problemin gerçek boyutlu örnekleri için kısa sürede kaliteli sonuçlar almak amacıyla, çalışma kapsamında bir sezgisel çözüm yöntemi geliştirilmiştir. Sezgisel yöntem, dört ana adımdan oluşmaktadır. Birinci adımda; işlerin ağırlıkları, zaman sınırına kalan süreleri, yetenek gereksinimleri ve ihtiyaç duydukları yeteneklerin teknisyen kümesindeki mevcudiyetine göre sıralanması gerçekleştirilir. İkinci adımda, işlerin yetenek gereksinimlerinin teknisyenlerin yetenekleri ile uyuşması dikkate alınarak ekiplerin oluşturulması ve ekiplere ilk işlerinin atanması gerçekleştirilir. Üçüncü adımda, bir önceki adımda atanamayan ișler ekiplere atanır. Son adımda ise, ekiplerin rotaları belirlenir. Sezgisel yöntem için notasyon bilgisi Ek A'da verilmiștir.

\section{1. İşlerin öncelik skorlarına göre siralanması}

İşlerin öncelik skorlarının belirlenmesi sırasında $\alpha_{i}$ ve $\boldsymbol{\beta}_{i}(\forall i \in N)$ olmak üzere iki değer göz önünde bulundurulmuştur.

Her iş $\boldsymbol{i} \in \boldsymbol{N}$ için; $\alpha_{\boldsymbol{i}}$ değeri, işin bulunduğu öncelik sınıfının ağırlığına $\left(\boldsymbol{w}_{\boldsymbol{i}}\right)$ ve zaman sınırlarına kalan süreye $\left(\boldsymbol{f}_{i}\right)$ bağlıdır ve Denklem (21) ile hesaplanır. Denklem (21)'e göre; bir $\boldsymbol{i} \in$ $\boldsymbol{N}$ işinin zaman sınırına kalan süresi günlük mesai süresine eşit ya da büyük ise, yalnızca işlerin ağırlıkları dikkate alınır ve $\alpha_{i}$ değeri $\boldsymbol{i}$ işinin ağırlığının tüm işlerin ağırlıklarının toplamına bölümü ile elde edilir. Diğer durumda, $\alpha_{i}$ değeri işlerin hem ağırlıklarına hem de zaman sınırına kalan sürelere bağlı olarak değişmektedir.

$$
\alpha_{i}=\left\{\begin{array}{cc}
\frac{w_{i} *\left(\tau-f_{i}\right)}{\sum_{i \in N} w_{i} *\left(\tau-f_{i}\right)} & f_{i} \leq \tau \text { ise }, \\
0 & \text { de ğilse. }
\end{array}\right.
$$

Her iş $\boldsymbol{i} \in \boldsymbol{N}$ için; $\boldsymbol{\beta}_{\boldsymbol{i}}$ değeri, işlerin yetenek gereksinimlerine ve teknisyenlerin yeteneklerine bağlıdır ve Denklem (22) 
ile hesaplanır. Denklem (22)'ye göre, $\boldsymbol{\beta}_{\boldsymbol{i}}$ değeri, $o$ iş için gerekli olan tüm yetenekler için yeteneğe sahip teknisyen sayısının toplam teknisyen sayısına oranının ortalamasıdır.

$$
\beta_{i}=\frac{\sum_{q \in Q} \frac{\sum_{t \in M} g_{t q}}{|M|} u_{i q}}{\sum_{q \in Q} u_{i q}}
$$

Her iş $\boldsymbol{i} \in \boldsymbol{N}$ için $\alpha_{\boldsymbol{i}}$ ve $\boldsymbol{\beta}_{\boldsymbol{i}}$ değerlerinin ağırlıklı toplamı ile bir skor elde edilir. İşler, öncelik skorlarına göre büyükten küçüğe sıralanır ve sıralı işler kümesi $\left(\boldsymbol{N}^{\boldsymbol{s}}\right)$ elde edilir. En büyük skora sahip olan iş, en öncelikli iş olarak ele alınır.

\subsection{Ekiplerin olușturulması ve ekiplere ilk işlerinin atanması}

$\mathrm{Bu}$ adımda, teknisyenlerden ekip oluşturulması ve her ekibe ilk işinin atanması gerçekleștirilmektedir.

Tüm teknisyenlerden oluşan atanmamış teknisyenler kümesi $(\boldsymbol{M})$ ile başlanır. Öncelik skorlarına göre sıralanan ișler sırayla ele alınır. Ele alınan işin yetenek gereksinimlerine bakılır, daha sonra, işin ihtiyacı olan yeteneklerin karşılanması için en uygun atanmamış teknisyen araması yapılır. $\mathrm{Bu}$ arama sırasında, iki ölçüden yararlanılmaktadır. Bunlar, teknisyenin yetenekleri ile işin yetenek gereksinimlerinin eşleşme sayısı ve işin teknisyenin bulunduğu bir ekibe atanması durumunda teknisyenin israf edilen yetenek sayısıdır. Bu iki ölçü doğrultusunda, öncelik skoru en yüksek işten başlanarak, sırasıyla her bir iş için, yetenekleri en çok eşleşen ve en az israf edilen yeterli sayıda teknisyen bulunduğu noktada, bu teknisyenlerden bir ekip oluşturulmaktadır. Bir ekibe atanan teknisyenler, atanmamıss teknisyenler kümesinden çlkarılmakta ve ekibi oluştururken kullanılan iş, ekibe atanmaktadır. Bir iş̧ için yetenek gereksinimlerine uygun atanmamış teknisyen bulunamaması durumunda is atanamayan işler $\left(\boldsymbol{N}^{-}\right)$listesine atılır.
Tüm teknisyenlerin bir ekibe atanması durumunda, ekip oluşturma işlemi tamamlanır ve henüz ekip ataması gerçekleştirilmemiş işler atanamayan işler listesine atılır. Bu adıma ilişkin sözde kod Ek B'da verilmiştir.

Sezgiselin ilk iki adımında, işlerin skorlarının ve mevcut teknisyen kümesinin yetenekleri ile işlerin yetenek gereksinimi uyumluluğunun belirlenmesi ve bu değerler kullanılarak ekiplerin oluşturulması ile ekiplere ilk işlerinin atanması ele alınmıștır. $\mathrm{Bu}$ durum, Cordeau vd. [4]'nin çalışmasında değerlendirmeye alınan tüm ölçülerin ağırlıklı ortalaması hesaplanarak tek bir adımda gerçekleştirilmektedir.

\subsection{Oluşturulan ekiplere kalan işlerin} atanması

Sezgiselin bu adımında, ekiplerin oluşturulması sırasında atanamayan işlerin, oluşturulmuş ekiplere atanması gerçekleştirilmektedir. Atanamayan işler listesindeki her bir iş için, işin ihtiyacı olan yeteneklerin karşılanması için en uygun ekip araması yapılmaktadır. Bir ekibin yetenekleri belirlenirken, ekipteki teknisyenlerin yeteneklerinin birleşimi kullanılmaktadır. Bir iş için en uygun ekibin bulunması sırasında, işin ihtiyacı olan fakat ekipte bulunmayan yetenek sayısı ve işin ekibe atanması durumunda israf edilecek yetenek sayısı ölçülerinden yararlanılmaktadır. Her bir atanamayan iş, işin tüm yetenek ihtiyaçlarını karşılayan ve işin ekibe atanması durumunda israf edilecek yetenek sayısını en küçükleyen ekibe atanmakta ve atanamayan işler listesinden çıkartılmaktadır. Ekiplerin gün içerisinde yapabilecekleri maksimum iş sayısını sınırlamak için 'günlük mesai süre limiti' dikkate alınarak iş ataması yapılmaktadır. Bunun için, bir ekibe atanan işlerin işlem süreleri toplamının, ekibin günlük mesai süresini aşmamasına dikkat edilmektedir. Bir işin yetenek ihtiyacını karşılayacak hiç bir ekip bulunamaması durumunda bu iş 
G. Kutayer Bilgin vd. / Öncelik Seviyelerine Sahip Çoklu Yetenek Gerektiren İșler için Ekip Olușturma, Çizelgeleme ve Rotalama

için ataması Küçük ölçekli problem örneklerinde; iş gerçekleştirilememektedir. $\mathrm{Bu}$ adıma sayısı, teknisyen sayısı, iş öncelik sınıfı ilişkin sözde kod Ek C'de verilmiştir.

\begin{tabular}{|c|c|c|c|}
\hline $\begin{array}{c}\text { İş } \\
\text { sayıs } \\
(|\boldsymbol{N}|) \\
\end{array}$ & $\begin{array}{c}\text { Teknisyen } \\
\text { sayısı } \\
(|\boldsymbol{M}|) \\
\end{array}$ & $\begin{array}{c}\text { Yetenek } \\
\text { sayısı } \\
(|\boldsymbol{Q}|)\end{array}$ & $\begin{array}{c}\text { Öncelik } \\
\text { sinıfi sayısı } \\
(|\boldsymbol{P}|) \\
\end{array}$ \\
\hline 3 & \multirow{4}{*}{9} & \multirow{4}{*}{3} & 2,3 \\
\hline 10 & & & $2,3,4$ \\
\hline 15 & & & $2,3,4$ \\
\hline 20 & & & $2,3,4$ \\
\hline
\end{tabular}
sayısı ve yetenek sayısı, Tablo 1'de gösterildiği gibi farklı değerleri alacak şekilde belirlenmiștir.

Tablo 1. Rastgele türetilmiş küçük ölçekli problem örnekleri kümesi için problem büyüklüklerine ilişkin bilgiler

Sezgisel çözüm yönteminin 5.4. Ekiplerin rotalarının belirlenmesi İşlerin ekiplere atanması sonucunda her bir ekibin o gün gerçekleștirmesi gereken işler belirlenir. Her bir ekibe atanan işlerin farklı konumlarda bulunması nedeniyle ortaya bir rotalama problemi çıkmaktadır. Çalışmamız kapsamında günlük probleme odaklanılması ve ekiplerin gün içerisinde aynı şehirde bulunan işlere yönlendirilmesi nedeniyle, işler arasındaki mesafelerin hesaplanmasında doğrusal (rectilinear) uzaklık hesaplama yöntemi kullanılmıştır.

Çalışmamızda, işlerin zaman sınırını aşılmayacak şekilde her bir işin, önceliği kendisinden düşük işlerden daha önce tamamlanması hedeflenmektedir. $\mathrm{Bu}$ doğrultuda; her ekip için, o ekibe atanan işlerin zaman sınırına kalan süresi ve önceliği dikkate alınarak, ekibin rotası oluşturulur. Bu adıma ilişkin sözde kod Ek D’de verilmiștir.

\section{Deneysel Çalışmalar}

\section{1. Problem \\ örneklerinin} oluşturulması

Geliștirilen çözüm yöntemlerinin performanslarını değerlendirmek amacıyla; hem rastgele türetilmiș veriler, hem de gerçekçi veriler kullanılarak problem örnekleri oluşturulmuştur.

6.1.1. Rastgele türetilmiş problem örneklerinin oluşturulması

Matematiksel modelin geçerlemesi ve sezgisel yöntemin performansının değerlendirilmesi amacıyla küçük ölçekli problem örnekleri oluşturulmuştur. performansının test edilmesi için türetilen büyük ölçekli problem örneklerine ilişkin iş sayısı, teknisyen sayısı, iş öncelik sınıfı sayısı ve yetenek sayısı değerleri Tablo 2'de verilmiştir.

Tablo 2. Rastgele türetilmiş büyük ölçekli problem örnekleri kümesi için problem büyüklüklerine ilişkin bilgiler

\begin{tabular}{|c|c|c|c|}
\hline $\begin{array}{c}\text { İș sayısı } \\
(|N|)\end{array}$ & $\begin{array}{c}\text { Teknisyen } \\
\text { sayısı } \\
(|\boldsymbol{M}|) \\
\end{array}$ & $\begin{array}{c}\text { Yetenek } \\
\text { sayısı } \\
(|\boldsymbol{Q}|) \\
\end{array}$ & $\begin{array}{c}\text { Öncelik } \\
\text { sinıfı sayısı } \\
(|\boldsymbol{P}|) \\
\end{array}$ \\
\hline 200 & \multirow{3}{*}{100} & \multirow{9}{*}{5} & \multirow{9}{*}{4} \\
\hline 300 & & & \\
\hline 400 & & & \\
\hline 300 & \multirow{3}{*}{200} & & \\
\hline 400 & & & \\
\hline 500 & & & \\
\hline 300 & \multirow{3}{*}{300} & & \\
\hline 400 & & & \\
\hline 500 & & & \\
\hline
\end{tabular}

Rastgele türetilmiş problem örnekleri için öncelik sınıflarının ağırlıkları, teknisyen çizelgeleme problemi üzerine çalışan Dutot vd. [27] çalışmasında ele aldığı gibi, $\boldsymbol{w}_{1}=28, \boldsymbol{w}_{2}=14, \boldsymbol{w}_{3}=4, \boldsymbol{w}_{4}=1$ olarak belirlenmiştir. Öncelik sınıfı sayısı 2 olan problem örneklerinde $\boldsymbol{w}_{\mathbf{1}}=28, \boldsymbol{w}_{\mathbf{2}}=14$ olarak, öncelik sınıfı sayısı 3 olan problem örneklerinde ise $\boldsymbol{w}_{\mathbf{1}}=28, \boldsymbol{w}_{\mathbf{2}}=14, \boldsymbol{w}_{\mathbf{3}}=$ 4 olarak alınmıştır.

\subsubsection{Gerçekçi problem örneklerinin} oluşturulması

Bir enerji dağıtım şirketi tarafından sağlanan gerçekçi veriler kullanılarak dört farklı enerji dağıtım bölgesi için problem örnekleri elde edilmiștir. Gerçekçi verilerde her bir bölge için ele 
G. Kutayer Bilgin vd. / Öncelik Seviyelerine Sahip Çoklu Yetenek Gerektiren İşler için Ekip Oluşturma, Çizelgeleme ve Rotalama

alınan yetenek sayısı 5'tir, öncelik sınıfı 4'te verilmektedir. Önceliklendirilmiş iki sayısı ise her bölge için farklılık amaç fonksiyonu için en iyi çözümü göstermektedir. Öncelik sınıflarının yakalamak adına Pareto optimal sonuçlar ağırlıkları veride sağlanmaktadır. raporlanmıştır. Tablo 4'te, her bir Gerçekçi problem örnekleri için problem örneği için; matematiksel parametre değerleri Tablo 3'te modelin ve sezgisel yöntemin sonuçları verilmiștir. $\mathrm{Bu}$ örneklerde, fazla mesai verilmektedir. Tabloda matematiksel zaman sınırı ile normal mesai zaman modelin sonuçları için; ağırlıklı $\boldsymbol{C}_{\boldsymbol{p}}^{\text {max }}$ sınırı birbirine eşit ve $480 \mathrm{dk}$. olarak toplamı, toplam maliyet, $M 1$ ve $M 2$ alınmıştır.

Tablo 3. Gerçekçi problem örnekleri için problem büyüklüklerine ilişkin bilgiler

\begin{tabular}{|l|c|c|c|c|}
\hline Problem örneği & 1 & 2 & 3 & 4 \\
\hline İş sayısı (|N|) & 40 & 52 & 335 & 403 \\
\hline Teknisyen sayısı $(|\boldsymbol{M}|)$ & 31 & 38 & 68 & 96 \\
\hline Ekip sayısı $(|\boldsymbol{E}|)$ & 7 & 7 & 41 & 45 \\
\hline Yetenek sayısı (|Q|) & 5 & 5 & 5 & 5 \\
\hline $\begin{array}{l}\text { Öncelik sınıfı sayısı } \\
(|\boldsymbol{P}|)\end{array}$ & 14 & 17 & 57 & 75 \\
\hline
\end{tabular}

\subsection{Deneysel çalışmalar}

Oluşturulan problem örneklerinin çözümü için, geliştirilen $M 1$ ve $M 2$ matematiksel modelleri Intel core i7, 2.5 $\mathrm{GHz}, 4 \mathrm{~GB}, 64$ bit özelliklerindeki bir bilgisayarda, CPLEX OPL 12.4 çözücüsü kullanılarak ayrı ayrı 4 saat zaman sınırı ile çözdürülmüştür. Geliştirilen sezgisel yöntem, Java programlama dilinde, Eclipse IDE for Java platformunda kodlanmış, koşturumlar aynı özelliklere sahip bir bilgisayarda gerçekleştirilmiştir.

Sezgisel yöntemin ilk adımında işlerin öncelik skorlarına göre sıralanmasında $\alpha$ ölçüsünün ağırlığı olan $\mathbf{w}_{\alpha}$ ve $\boldsymbol{\beta}$ ölçüsünün ağırlığı olan $\mathbf{w}_{\boldsymbol{\beta}}$ değerleri, her bir problem örneği için 0,1 ile 0,9 aralığında değiştirilmiş ve en iyi amaç fonksiyonu değerlerini veren $\mathbf{w}_{\alpha}$ ve $\mathbf{w}_{\boldsymbol{\beta}}$ değerlerine ilişkin sonuçlar kabul edilmiştir.

6.2.1. Matematiksel model ve sezgisel yöntemin karşılaştırmalı sonuçları

Rastgele türetilmiş küçük problem örnekleri için matematiksel modelin ve sezgisel yöntemin ürettiği sonuçlar Tablo

modelleri için optimalden uzaklık (gap), ve çalışma süresi bilgileri bulunmaktadır. Tabloda sezgisel yöntemin sonuçları için; ağırlıklı $\boldsymbol{C}_{\boldsymbol{p}}^{\text {max }}$ toplamı, maliyet bilgileri ve bu amaç fonksiyonu değerlerinin matematiksel model ile elde edilen amaç fonksiyonu değerlerinden yüzde sapmaları (sapma1 ve sapma2 sütunlarında) verilmektedir. $\mathrm{Bu}$ bölümdeki tüm örnekler için sezgisel yöntem 1 saniyeden kısa sürede sonuç vermiştir.

Tablo 4'te görüldüğü gibi, az sayıda iş içeren küçük boyutlu problemler için $(|\boldsymbol{N}| \leq 10)$ matematiksel model ile kabul edilebilir sürede optimal (her iki model için gap değerinin 0 olduğu) sonuçlar elde edilirken, iș sayısının 15 olduğu örnekler için, M2 modelinin verilen zaman sınırında optimal sonuç bulamadığ gözlenmiştir. İş sayısının 15 olduğu örneklerde, verilen zaman sinırında M1 modelinin sonucunun optimalden uzaklığının (gap) \%14-20 arasında olduğu, M2 modelinin sonucunun optimalden uzaklığının ise \%30,5'a kadar yükseldiği görülmüștür. İș sayısının 20 olduğu örnekler için ise, verilen zaman sinırında $M 2$ modeli $M 1$ modelinin çözümünden daha düşük toplam maliyete sahip bir çözüm üretememiştir. Sezgisel çözüm yönteminden elde edilen sonuçlar, matematiksel modelden elde edilen sonuçlar ile karşılaştırıldığında, sezgisel yöntem ile 1 saniyeden kısa sürede ağırlıklı $\boldsymbol{C}_{\boldsymbol{p}}^{\max }$ toplamı için ortalama $\% 12.06$, en yüksek \%24.52 sapmaya sahip, iyi sonuçlar elde edildiği sonucuna ulaşılmaktadır. Sezgiselin sonuçlarında toplam maliyet açısından iyileştirme 
G. Kutayer Bilgin vd. / Öncelik Seviyelerine Sahip Çoklu Yetenek Gerektiren İșler için Ekip Olușturma, Çizelgeleme ve Rotalama

yapılması gelecek çalışma olarak için elde edilen her iki sonuç için; ekip planlanmaktadır. sayısı $(|\boldsymbol{E}|)$, atanamayan iş sayısı $\left(\left|\boldsymbol{N}^{-}\right|\right)$, ağırlıklı $\boldsymbol{C}_{\boldsymbol{p}}^{\max }$ toplamı ve maliyet bilgileri

6.2.2. Rastgele türetilmiş büyük problem örnekleri için sezgisel sonuçları

Rastgele türetilmiş büyük problem örnekleri için sezgisel yöntem ile elde edilen sonuçlar Tablo 5'te verilmektedir. Bu bölümdeki tüm örnekler için sezgisel yöntem 1 saniyeden kısa sürede sonuç vermiştir. Tablo 5'te görüldüğü gibi; iş sayısı arttıkça, ağırlıklı $\boldsymbol{C}_{\boldsymbol{p}}^{\max }$ toplamı ve maliyet artmaktadır. Aynı iș sayısı için, teknisyen sayısı arttıkça ekip sayısının artması, ekip başına düşen iş sayısının azalması ve böylelikle ișlerin daha erken tamamlanabilmesi nedeniyle ağırlıklı $\boldsymbol{C}_{\boldsymbol{p}}^{\max }$ toplamının azaldığ $\mathrm{g}$ fakat ekip sayısının artması nedeniyle üçgen eşitsizliğine bağlı olarak seyahat maliyetinin artmasından dolayı toplam maliyetlerin arttığ gözlemlenmiștir.

\subsubsection{Gerçekçi problem örnekleri için sezgisel sonuçları}

Sezgisel çözüm yönteminin gerçekçi problem örnekleri için değerlendirilmesinde, öncelikle ekip oluşturmanın sistematik yapılmasının katkısı analiz edilmiştir. Her gerçekçi problem örneği için, hâlihazırda şirket tarafından kurulmuș olan mevcut ekipler kullanılarak sezgisel yöntemin son iki adımının koşulması sonucunda elde edilen sonuçlar ile ekip olușturulmasının da sezgisel yöntem tarafindan gerçekleștirildiği sonuçlar Tablo 6'da verilmektedir. Tablo 6'da her bir örnek sunulmaktadır. Sonuçlarda, herhangi bir iş için gecikme durumu olmaması ve bu örneklerde fazla mesai zaman sınırı ile normal mesai zaman sınırının birbirine eşit olması nedeniyle, Tablo 6'da maliyet sütununda verilen bilgi seyahat maliyetini ifade etmektedir. Sonuçlarda atanamayan işlerin bulunmasının nedeni, ekiplerin günlük mesai süre limitlerinin dolması veya bazl işlerin yetenek gereksinimlerinin mevcut ekipler tarafından karşılanamamasıdır. İş sayısı 40 ve 52 olan problem örnekleri için, sezgisel ile oluşturulan ekiplerin sayıları, mevcut ekiplerin sayısından daha fazladır. $\mathrm{Bu}$ durum, ağırlıklı $\boldsymbol{C}_{\boldsymbol{p}}^{\max }$ toplamında azalma sağlamıștır. $\mathrm{Bu}$ örneklerde sezgisel ile oluşturulan ekipler ile elde edilen sonuçlarda maliyetlerin daha yüksek olmasının sebebi ise, ekip sayısının daha fazla olmasıdır. İș sayısı 335 ve 403 olan problem örnekleri için ise, ekip oluşturmanın sezgisel yöntem tarafından gerçekleștirildiği sonuçlarda atanamayan iș sayısı, sırasıyla, $\% 40$ ve $\% 74$ daha düşüktür. Bu örnekler için, ağırlıklı $\boldsymbol{C}_{\boldsymbol{p}}^{\max }$ toplamı değerinin mevcut ekipler kullanıldığında daha düşük olmasının sebebi, ekiplere atanabilen iş sayısının daha düşük olmasıdır. Sezgiselin kurduğu ekipleri içeren sonuçlarda maliyetlerin daha yüksek olmasının nedeni ise, hem daha fazla işin ekiplere atanması hem de ekip sayısının daha fazla olmasıdır. 
G. Kutayer Bilgin vd. / Öncelik Seviyelerine Sahip Çoklu Yetenek Gerektiren İşler için Ekip Oluşturma, Çizelgeleme ve Rotalama

Tablo 4. Matematiksel model ile sezgisel yöntemin rastgele türetilmiş küçük problem örnekleri kullanılarak karşılaştırılması

\begin{tabular}{|c|c|c|c|c|c|c|c|c|c|c|}
\cline { 3 - 12 } \multicolumn{1}{|c|}{} & \multicolumn{9}{|c|}{ Matematiksel Model } & \multicolumn{4}{c|}{ Sezgisel Yöntem } \\
\hline$|\boldsymbol{N}|$ & $|\boldsymbol{P}|$ & $\begin{array}{c}\text { Ağırlıklı } \\
\boldsymbol{C}_{\boldsymbol{p}}^{\text {max }} \\
\text { Toplamı }\end{array}$ & $\begin{array}{c}M 1 \\
\text { Gap } \\
(\%)\end{array}$ & $\begin{array}{c}\text { Toplam } \\
\text { Maliyet } \\
(\mathrm{TL})\end{array}$ & $\begin{array}{c}M 2 \\
\text { Gap } \\
(\%)\end{array}$ & $\begin{array}{c}\text { Süre } \\
(\mathrm{dk})\end{array}$ & $\begin{array}{c}\text { Ağırlıklı } \\
\boldsymbol{C}_{\boldsymbol{p}}^{\text {max }} \\
\text { Toplamı }\end{array}$ & $\begin{array}{c}\text { Sapma1 } \\
(\%)\end{array}$ & $\begin{array}{c}\text { Toplam } \\
\text { Maliyet } \\
(\mathrm{TL})\end{array}$ & $\begin{array}{c}\text { Sapma2 } \\
(\%)\end{array}$ \\
\hline 3 & 2 & 37 & 0 & 3,68 & 0 & $<1$ & 37 & 0 & 3,68 & 0 \\
\hline 3 & 3 & 137 & 0 & 3,68 & 0 & $<1$ & 137 & 0 & 3,68 & 0 \\
\hline 10 & 2 & 67 & 0 & 20,7 & 0 & $<1$ & 79 & 17,39 & 20,8 & 0,48 \\
\hline 10 & 3 & 244 & 0 & 20,7 & 0 & $<1$ & 263 & 7,78 & 21,16 & 2,2 \\
\hline 10 & 4 & 596 & 0 & 20,7 & 0 & $<1$ & 647 & 8,56 & 21,16 & 2,2 \\
\hline 15 & 2 & 71 & 14,08 & 21,62 & 30,50 & 240 & 83 & 16,90 & 28,06 & 30,4 \\
\hline 15 & 3 & 243 & 19,75 & 21,16 & 11,10 & 240 & 276 & 13,58 & 29,9 & 41,3 \\
\hline 15 & 4 & 545 & 18,35 & 23,46 & 3,54 & 240 & 677 & 24,22 & 25,76 & 9,8 \\
\hline 20 & 2 & 118 & 91,24 & 31,28 & 91,24 & 240 & 123 & 4,24 & 38,64 & 23,5 \\
\hline 20 & 3 & 356 & 58,99 & 25,76 & 58,99 & 240 & 411 & 15,44 & 39,56 & 61,33 \\
\hline 20 & 4 & 893 & 91,60 & 23,9 & 91,60 & 240 & 1112 & 24,52 & 39,56 & 65,52 \\
\hline
\end{tabular}

Tablo 5. Rastgele türetilmiş büyük ölçekli problem örnekleri için sezgisel yöntem ile elde edilen sonuçlar

\begin{tabular}{|c|c|c|c|}
\hline$|N|$ & $|\boldsymbol{M}|$ & Ağırlıklı $C_{\boldsymbol{p}}^{\max }$ toplamı & Toplam Maliyet (TL) \\
\hline 200 & \multirow{3}{*}{100} & 259.600 & 2.173 \\
\hline 300 & & 257.860 & 2.432 \\
\hline 400 & & 283.290 & 2.489 \\
\hline 300 & \multirow{3}{*}{200} & 257.240 & 5.297 \\
\hline 400 & & 265.430 & 5.320 \\
\hline 500 & & 269.160 & 5.543 \\
\hline 300 & \multirow{3}{*}{300} & 249.200 & 7.985 \\
\hline 400 & & 253.780 & 7.626 \\
\hline 500 & & 275.630 & 7.502 \\
\hline
\end{tabular}

Tablo 6. Mevcut ekipler ile alınan sezgisel sonuçları ve ekiplerin de sezgisel ile oluşturulmasıyla alınan sezgisel sonuçları

\begin{tabular}{|c|c|c|c|c|c|c|c|c|c|c|}
\hline \multirow[b]{2}{*}{$|N|$} & \multirow[b]{2}{*}{$|\boldsymbol{P}|$} & \multirow[b]{2}{*}{$|\boldsymbol{M}|$} & \multicolumn{4}{|c|}{ Mevcut ekipler ile alınan sonuçlar } & \multicolumn{4}{|c|}{$\begin{array}{l}\text { Sezgisel ile oluşturulan ekipler ile alınan } \\
\text { sonuçlar }\end{array}$} \\
\hline & & & $|\mathbf{E}|$ & $\left|N^{-}\right|$ & $\begin{array}{c}\text { Ağırlıklı } \\
C_{p}^{\text {max }} \text { toplamı }\end{array}$ & $\begin{array}{c}\text { Maliyet } \\
\text { (TL) }\end{array}$ & $|\mathbf{E}|$ & $\left|N^{-}\right|$ & $\begin{array}{c}\text { Ağırlıklı } \\
C_{p}^{\text {max }} \text { toplamı }\end{array}$ & $\begin{array}{l}\text { Maliyet } \\
\text { (TL) }\end{array}$ \\
\hline 40 & 14 & 31 & 7 & 6 & 3.672 & 67 & 15 & 6 & 2.292 & 267 \\
\hline 52 & 18 & 38 & 7 & 9 & 8.495 & 201 & 43 & 9 & 2.105 & 904 \\
\hline 335 & 57 & 68 & 41 & 223 & 25.129 & 604 & 42 & 88 & 25.471 & 1.442 \\
\hline 403 & 75 & 96 & 45 & 259 & 28.244 & 671 & 52 & 69 & 38.483 & 1.779 \\
\hline
\end{tabular}

\section{Sonuç ve Değerlendirme}

Çalışmamızda; genelde, teknisyenlerin müşteri noktalarında sundukları servis hizmetleri, evde sunulan sağlık hizmetleri, güvenlik şirketlerinin sundukları kontrol hizmetleri vb. alanlarda gözlenen yerinde servis hizmetlerinde, özelde ise, enerji dağıtım sektöründe operasyonel düzeyde gözlemlenen işgücü çizelgeleme ve rotalama problemi ele alınmıștır. Literatürde yer alan diğer çalıșmalardan farklı olarak, çalışmamızda; farklı coğrafi konumlarda bulunan, farklı yetenek gereksinimlerine ve önceliklere sahip işlerin, farklı yeteneklere sahip teknisyenlerden işlerin ihtiyaçlarına uygun olarak oluşturulan ekiplere atanması ve ekiplerinin günlük rotalarının belirlenmesi hedeflenmiştir. 
Gerçek hayatta karşılaşılan probleme benzer şekilde iki öncelikli amaç ele alınmıştır. Birinci öncelikli amaç, önceliklerine göre ağırlıklandırılmıș iș sınıflarının tamamlanma sürelerinin ağırlıklı toplamını en küçüklemektir. İkinci öncelikli amaç ise; günlük operasyonel maliyetleri en küçüklemektir.

Çalışmamızda, öncelikle problem için bir matematiksel model geliştirilmiştir. Ancak matematiksel modelin büyük ölçekli problem örnekleri için kabul edilebilir sürede kaliteli sonuçlar üretememesi nedeniyle bir sezgisel yöntem geliştirilmiştir.

Sezgisel yöntem, hem rastgele türetilmiş hem de gerçekçi veriler üzerinde test edilmiş, hızlı ve çözüm kalitesi yüksek sonuçlar elde edilmiştir. Gerçekçi problem örnekleri için, mevcut ekipler kullanılarak sezgisel yöntemin bulduğu sonuçlar ile ekiplerin de sezgisel yöntem tarafından oluşturulduğu sonuçlar karşılaştırılmıştır. Ekiplerin de sezgisel yöntem kullanılarak oluşturulması ile daha fazla işin ekiplere atanabildiği ve işlerin daha kısa sürede tamamlandığı gözlenmiștir.

\section{Teşekkür}

Bu çalışma, 117M577 No'lu TÜBİTAK 3501 projesi tarafından desteklenmiștir. Çalışmanın çeşitli aşamalarındaki katkılarından dolayı Seray Çakırgil'e teşekkür ederiz.

\section{Kaynakça}

[1] Fikar, C. and Hirsch P., 2016. Home health care routing and scheduling: A review, Computers \& Operations Research, 77, 86-95, 2017.

[2] Cheng, E. and Rich, J. L., 1998. A home health care routing and scheduling problem, Technical Report 98-04, Computational and Applied Mathematics, Rice University
[3] Eveborn, P, Rönnqvist, $\mathrm{M}$, Einarsdottir, H, Eklund, M, Lidén, $K$, Almroth, M., 2009. Operations Research Improves Quality and Efficiency in Home Care, Interfaces, Vol. 39, No. 1, 18-34, DOI 10.1287/inte.1080.0411

[4] Cordeau, J.-F., Laporte, G., Pasin, F., and Ropke, S., 2010. Scheduling Technicians and Tasks in a Telecommunications Company, Journal of Scheduling, 13, 393-409. 18

[5] Misir, M., Smet, P., Verbeeck, K., and Vanden Berghe, G. 2011. Security personnel routing and rostering: a hyper-heuristic approach. In Proceedings of the 3rd International Conference on Applied Operational Research, ICAOR2011, Istanbul, Turkey, pages 193-205

[6] Allaoua, H., Borne, S., L'etocart, L., and Calvo, R. W., 2013. A matheuristic approach for solving a home health care problem, Electronic Notes in Discrete Mathematics, 41 (0):471 - 478, 2013

[7] Kovacs, A., Parragh, A. A., Doerner, K. F., Hartl, R. F., 2012. Adaptive large neighborhood search for service technician routing and scheduling problems, Journal of Scheduling, 15(5) 579-600.

[8] Trautsamwieser, A., \& Hirsch, P., 2014. A branch-price-and-cut approach for solving the mediumterm home health care planning problem, Networks 64(3), 143-159

[9] Zamorano, E., \& Stolletz, R., 2016. Branch-and-price approaches for the Multiperiod Technician Routing and Scheduling Problem, European Journal of Operational Research, 257(1), 55-68

[10] Firat, M. and Hurkens, C. A. J., 2012. An improved MIP-based approach for a multi-skill workforce scheduling problem, Journal of Scheduling, vol. 15 , pp. $363-380$ 
G. Kutayer Bilgin vd. / Öncelik Seviyelerine Sahip Çoklu Yetenek Gerektiren İşler için Ekip Oluşturma, Çizelgeleme ve Rotalama

[11] Rasmussen, M. S., Justesen, T., Dohn, A., \& Larsen, J. (2012). The home care crew scheduling problem: Preference-based visit clustering and temporal dependencies. European Journal of Operational Research, 219(3), 598-610

[12] Hiermann, G., Puchinger, J., Ropke, S., and Hartl, R. F., 2015. The Electric Fleet Size and Mix Vehicle Routing Problem with Time Windows and Recharging Stations, Transportation Science. In press.

[13] Misir, M., Smet, P., \& Vanden Berghe, G., 2015. An analysis of generalised heuristics for vehicle routing and personnel rostering problems. Journal of the Operational Research Society, 66(5), 858-870.

[14] Fosgerau, M., Engelson, L., 2011. The value of travel time variance. Transportation Research Part B 45, 1-8.

[15] Bostel, N., Dejax, P., Guez, P., \& Tricoire, F., 2008. Multiperiod planning and routing on a rolling horizon for field force optimization logistics. In Bruce Golden, S. Raghavan, \& Edward Wasil (Eds.). The vehicle routing problem: Latest advances and new challenges (43, pp. 503-525).

[16] Barrera, D., Velasco, N., \& Amaya, C.A., 2012. A network-based approach to the multi-activity combined timetabling and crew scheduling problem: Workforce scheduling for public health policy implementation. Computers \& Industrial Engineering, 63(4), 802-812.

[17] Goel, A., Meisel, F., 2013. Workforce routing and scheduling for electricity network maintenance with downtime minimization. European Journal of Operational Research 231 (1), 210-228

[18] Francis, P.M., Smilowitz, K.R., Tzur, M., 2008. The period vehicle routing problem and its extensions. In: Golden BL, Raghavan S, Wasil E, editors. The vehicle routing problem: latest advances and new challenges.

[19] Blakeley, F., Bozkaya, B., Cao, B., Hall, W., Knolmajer, J., 2003. Optimizing periodic maintenance operations for Schindler Elevator Corporation. Interfaces 33 (1), 67-79

[20] Tang, H., Millerhooks, E. and Tomastik, R., 2007. Scheduling technicians for planned maintenance of geographically distributed equipment. Transportation Research Part E - Logistics and Transportation Review 43 (2007) 591-609

[21] Shao, Y., Jonathan, F. B. and Jarrah, A. I., 2012. The therapist routing and scheduling problem, IIE Trans. Oper. Eng. Anal. 44 (10) (2012) 868-893

[22] Bard, J. F., Shao, Y. and Jarrah, A. I., 2014. A sequential GRASP for the therapist routing and scheduling problem, J. Sched. 17 (2) (2014) 109-133.

[23] Hindle, T., Hindle, A., Spollent, M., 2000. Resource allocation modelling for homebased health and social care services in areas having differential population density levels: a case study in Northern Ireland. Health Services Management Research 13, 164-169

[24] Rest K. D., Hirsch P., 2015. Daily scheduling of home health care services using time-dependent public transport, Flexible Services and Manufacturing Journal.

[25] Lanzarone, E., Matta, A., 2014. Robust nurse-to-patient assignment in home care services to minimize overtimes under continuity of care, Oper. Res. Health Care 3 (2), 48-58.

[26] Yuan, B., Liu, R., \& Jiang, Z., 2015. A branch-and-price algorithm for the home health care scheduling and routing problem with stochastic service times and skill requirements, International Journal of Production Research, 53(24), 7450-7464 
G. Kutayer Bilgin vd. / Öncelik Seviyelerine Sahip Çoklu Yetenek Gerektiren İşler için Ekip Oluşturma, Çizelgeleme ve Rotalama

[27] Dutot, P., Laugier, A. \& Bustos, A. 2006. Technicians and Interventions Scheduling for Telecommunications. Technical report, France Telecom R\&D. 18

\section{Ekler}

Ek A. Sezgisel Yöntem için Notasyon

$N^{s}$ : Sıralı işler kümesi

$\tau:$ Günlük mesai süresi

$M$ : Atanmamıș teknisyen kümesi

$Q$ : Yetenek kümesi

$E$ : Ekip kümesi

$w_{i}: i \in N$ işinin ait olduğu iş öncelik sinıfının ağırlığı

$f_{i}: i \in N$ ișinin zaman sınırına kalan süre $Q_{i}^{I}: i \in N$ işi için gerekli yetenek kümesi $p_{i}: i \in N$ işinin işlem süresi

$t_{i j}: i$ ve $j$ işleri arası süre bazında mesafe,

$\forall(i, j) \in A$

$u_{i q}:$ İş - yetenek matrisi

$g_{m q}$ : Teknisyen - yetenek matrisi

$N^{-}$: Atanamayan işler kümesi

$N_{e}: e \in E$ ekibine atanan işler kümesi

$N_{e}^{s}: e \in E$ ekibi için sıralı işler kümesi

$t_{e}: e \in E$ ekibinin toplam rotalama ve işlem süresi

$Y_{m}:$ İșin gerektirdiği ve $m \in M$ teknisyenin sahip olduğu yetenek sayısı $Y_{m}^{+}$: İşin gerektirmediği ancak $m \in M$ teknisyenin sahip olduğu yetenek sayısı $m^{*}$ : En uygun teknisyen

$Y_{e}^{-}$: İșin gerektirdiği ancak $e \in E$ ekibinin sahip olmadığ $\breve{l}_{\text {yetenek sayısı }}$

$Y_{e}^{+}$: İşin gerektirmediği ancak $e \in E$ ekibinin sahip olduğu yetenek sayısı $e^{*}$ : En uygun ekip

Ek B. Algoritma 1 - Ekiplerin olușturulması ve ekiplere ilk işlerinin atanması

Girdi: $N^{s} ; M ; Q ; p_{i}, \forall i \in N ; u_{i q}, \forall i \in$ $N, q \in Q ; g_{m q}, \forall m \in M, q \in Q$

Çוktı: $N_{e} ; N^{-} ; E ; t_{e}, \forall e \in E$

$E \leftarrow \varnothing$

$N^{-} \leftarrow \varnothing$

Her bir $i \in N^{s}$ için yap

$$
\begin{aligned}
& e \leftarrow \emptyset \\
& N_{e} \leftarrow \varnothing \\
& Q_{i}^{I}=\left\{q \in Q \mid u_{i q}=1\right\}
\end{aligned}
$$

Koşul $Q_{i}^{I}>0$ iken

\section{Her bir $m \in M$ için yap}

$$
\begin{aligned}
& Y_{m} \leftarrow 0 \\
& Y_{m}^{+} \leftarrow 0
\end{aligned}
$$

$$
\text { Her bir } q \in Q \text { için yap }
$$$$
\text { Eğer } u_{i q}=1 \text { ve } g_{m q}=1 \text { ise }
$$$$
Y_{m} \leftarrow Y_{m}+1
$$

\section{Son eğer}

$$
\text { Ĕger } u_{i q}=0 \text { ve } g_{m q}=1 \text { ise }
$$

$$
Y_{m}^{+} \leftarrow Y_{m}^{+}+1
$$

\section{Son eğer}

Son için

Son için

$$
\begin{aligned}
& m^{*}=\operatorname{argmax}_{m \in M}\left\{Y_{m}-Y_{m}^{+}\right\} \\
& \text {Eğer } m^{*}=\text { null ise } \\
& N^{-} \leftarrow N^{-} \cup\{i\} \\
& \text { Değilse } \\
& \quad Q_{i}^{I} \leftarrow Q_{i}^{I} \backslash\left\{q \in Q \mid g_{m^{*} q}=1\right\} \\
& \quad e \leftarrow e \cup m^{*} \\
& M \leftarrow M \backslash m^{*} \\
& \quad \text { Son eğer } \\
& \text { Son koşul } \\
& E \leftarrow E \cup\{e\} \\
& N_{e} \leftarrow N_{e} \cup\{i\} \\
& t_{e} \leftarrow p_{i}
\end{aligned}
$$

\section{Son koşul}

\section{Son için}

Ek C. Algoritma 2 - Oluşturulan ekiplere kalan işlerin atanması

Girdi: $N^{-} ; E ; Q ; p_{i}, f_{i}, \forall i \in N ; t_{e}, N_{e}$, $\forall e \in E ; u_{i q}, \quad \forall i \in N, q \in Q ; g_{t q}, \forall t \in$ $M, q \in Q$

Cıktı: $N^{-} ; t_{e}, N_{e}, \forall e \in E$

Her bir i $\in N^{-}$için yap

Her bir $e \in E$ için yap

Her bir $q \in Q$ için yap

Eğer $u_{i q}=1$ ve $g_{e q}=0$ ise

$$
Y_{e}^{-} \leftarrow Y_{e}^{-}+1
$$

\section{Son eğer}

Eğer $\boldsymbol{u}_{\boldsymbol{i q}}=0$ ve $\boldsymbol{g}_{\boldsymbol{e q}}=1$ ise

$$
Y_{e}^{+} \leftarrow Y_{e}^{+}+1
$$

\section{Son eğer}

Son için

\section{Son için}

Eğer $\left(t_{e}+p_{i} \leq f_{i}\right)$ ise

$e^{*}=\operatorname{argmax}_{e \in E}\left\{Y_{e}^{+} \mid Y_{e}^{-}=0\right\}$

\section{Son eğer}

Ĕger $\left(e^{*} \neq\right.$ null $)$ ise

$$
\begin{aligned}
& t_{e} \leftarrow t_{e}+p_{i} \\
& N_{e} \leftarrow N_{e} \cup\{\mathrm{i}\} \\
& N^{-} \leftarrow N^{-} \backslash\{i\}
\end{aligned}
$$

Son eğer

\section{Son için}


G. Kutayer Bilgin vd. / Öncelik Seviyelerine Sahip Çoklu Yetenek Gerektiren İşler için Ekip Oluşturma, Çizelgeleme ve Rotalama

Ek D. Algoritma 3 - Ekiplerin rotalarının belirlenmesi

Girdi: $E ; \quad N^{-} ; \tau ; N_{e}, \forall e \in E ; p_{i}, \quad f_{i}$, $w_{i}, \forall i \in N ; t_{i j}, \forall(i, j) \in A$

Çıktı: $N^{-}, N_{e}^{S}, \forall e \in E$

Her bir $e \in E$ için yap

$N_{e}^{S} \leftarrow \emptyset$

$k \leftarrow 0$

$t_{e} \leftarrow 0$

Koşul $N_{e} \neq \emptyset$ iken

$i \leftarrow \arg \min _{\left\{\mathrm{i} \in N^{+}\right\}}\left\{\frac{f_{i}-p_{i}-t_{e}}{w_{i}}\right\}$

Eğer $\left(t_{e}+t_{k i}+p_{i} \geq \tau\right)$ ise

$N^{-} \leftarrow N^{-} \cup\{i\}$

Değilse

$N_{e}^{S} \leftarrow N_{e}^{s} \cup\{i\}$

$t_{e} \leftarrow t_{e}+t_{k i}+p_{i}$

$k \leftarrow i$

Son eğer

$N_{e} \leftarrow N_{e} \backslash\{i\}$

Son koşul

Son için 